\title{
MULTIPOINT ULTRASONIC DIAGNOSTICS SYSTEM OF PRESTRESSED T-BEAMS
}

\begin{abstract}
A. MARIAK ${ }^{1}, \mathrm{~K} . \mathrm{WILDE}^{2}$
This paper is devoted to the application of ultrasonic wave propagation phenomena for the diagnostics of prestressed, concrete, bridge T-beams. A multi-point damage detection system is studied with use of numerically obtained data. The system is designed to detect the presence of the material discontinuities as well as their location.
\end{abstract}

Keywords: ultrasonic testing, prestressed beam of T-shaped, numerical simulation

\section{INTRODUCTION}

Use of precast concrete elements is common for the building industry in the most developed countries since it can optimize the consumption of energy, lower usage of materials and reduce building expenses [1] and it can be beneficial also for bridges [2]. The production of large prefabricated elements takes place in factory, and therefore high quality products can be manufactured. These products with high durability, requirements on aesthetics and performance need special quality control procedures. This paper is devoted to study of proposed damage detection system for precast, prestressed, concrete, T-shaped bridge beams (Figure 1). The superstructure of the bridge consists of set of T-shaped beams arranged in parallel with spacing of $0.90 \mathrm{~m}$. Such superstructures are designed for the moving load class A by PN-85/S-10030 and load by a vehicle of special class 150 according to STANAG standard.

In order to increase the use of prefabrication in civil infrastructure it is necessary to ensure the highest quality of the product by providing possibly simple quality control methods on each stage of construction process, i.e., during the production in the factory, storage and in some special cases also during transportation and even after mounting them on bridgeheads.

1 Department of Structural Mechanics, Faculty of Civil and Environmental Engineering, Gdansk Univeristy of Technology, e-mail: aleksandra.mariak@pg.gda.pl

2 Department of Structural Mechanics, Faculty of Civil and Environmental Engineering, Gdansk University of Technology, e-mail: krzysztof.wilde@pg.gda.pl 


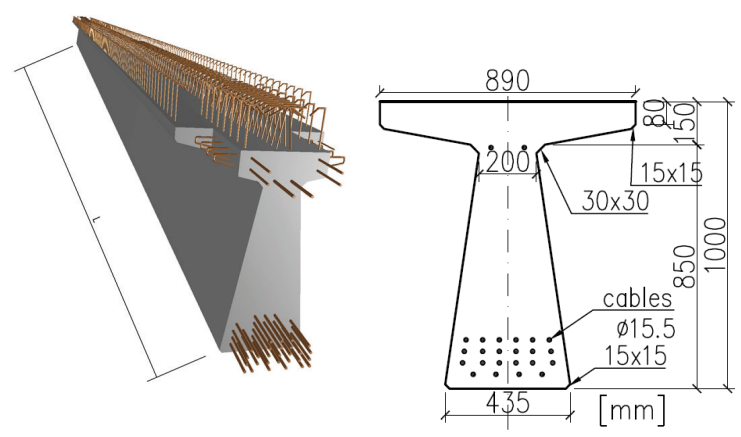

Fig. 1. Prefabricated beam T 24 [www.pw-comfort.com.pl]

\subsection{The QUALity CONTROL, DELIVERY, STORAGE}

The production process of precast elements consists of the following technological steps: preparation of forms, reinforcement, shaping, maturity and stripping. According to the regulations control of precast, prestressed, concrete, beams should be carried out at the factory. It involves the control of the type and grade of materials used to produce beams on the basis of the documentation (certificates, protocols, etc.) for compatibility with the relevant standards and design documentation. The control at the construction site should include: assessment of the overall appearance of the material and the check of values of geometrical dimensions with comparison to the requirements described in the appropriate standards. The surface of prefabricated elements should be smooth and inequalities and defects should not exceed the prescribed rates of deviation. The cracks and flaws on the surface of prestressed concrete elements are not permitted. Unacceptable are also cracks inside the material of the element. Various types of voids in precast elements are permissible within the limits given in PN-91/S-10042 and PN-S-10040: 1999 for reinforced concrete elements.

Delivery of precast elements should be planned according to the general erection sequence to minimize unnecessary site storage and handling. Transport of precast elements requires actions following strictly defined procedures. The elements can be transported after the concrete has reached at least $80 \%$ of the designed strength. As these elements have not gained their full designed strength, they are generally more susceptible to damages during handling. Impact and shock which can cause mechanical damage to the edges during handling elements, their transport, assembly and re-setting are unacceptable. Appropriate stacking method should be used to store the precast concrete elements (Figure 2) to prevent any undue stresses and damages.

A common cause of damage of prestressed T-beams is due to incorrect transport, storage or improper installation procedure (Figure 2). The resulting damage do not comply with the above mentioned requirements. 

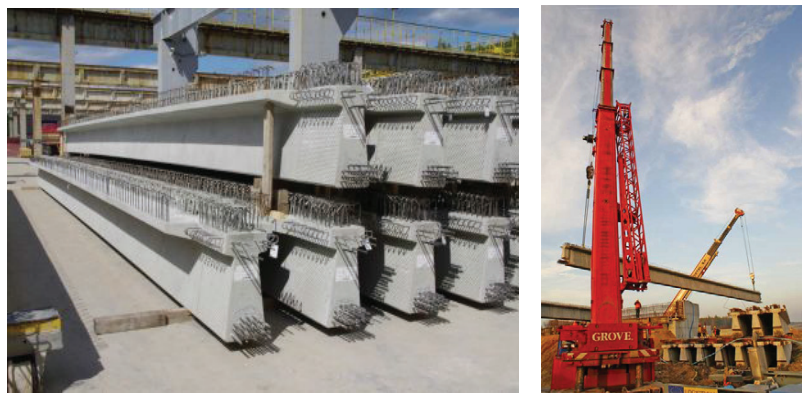

Fig. 2. The storage and assembly of a T-shaped beam [www.sibet.com.pl, www.pw-comfort.com.pl]

\subsection{UltRASONIC DiAgNOSTICS}

The nondestructive acoustic techniques used to test concrete structures are divided into: ultrasonic, impact echo and impulse response methods [3], [4]. The ultrasonic methods consists of pulse transmission (passage technique), pulse echo (reflection), time-offlight diffraction. All these methods allow quick assessment of the quality of concrete without interfering with the structure of the tested material.

In the simplest form, the ultrasonic diagnostics is based on wave generated at one location in a form of an impulse and recorded in some other location by piezoelectric transducer [5]. The information stored in the recorded acceleration signal contains data on wave reflection from the material discontinuities. Knowledge on wave velocity in concrete together with analysis of acceleration records allows to detect the presence of the damage and estimate its location (e.g., [3], [6]).

An ultrasonic wave that undergoes reflection from both the discontinuities and geometric boundary condition of the beam becomes very complicated as it travels through the tested element. Ultrasonic diagnostics can be supported by application of wave packets generated by piezoelectric transducers instead of waves crated from impulse loading. This method combines passage method based on the effect of transferring the wave by a discontinuity with the method TOFD (time of flight diffraction) which uses phenomenon of diffraction and scattering wave deflection. In addition advanced signal processing in time and frequency domain might be employed to improve information extraction from the recorded signals [7].

The relation between the longitudinal wave speed (P-wave) $c_{p}$ and time of flight $t_{h}$ is as follows:

$$
c_{p}=\frac{h}{t_{h}}
$$

where $h$ stands for waveform path, i.e. element thickness, $h$, or defect depth, $d$ [3]. The principle of the passage technique is presented in Figure 3. 


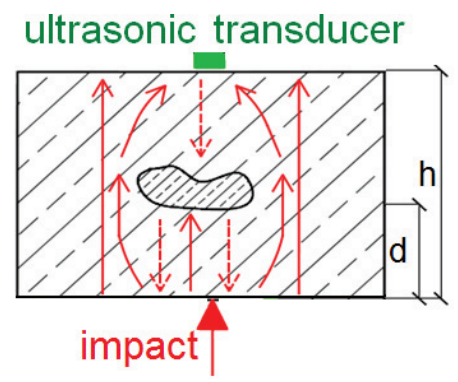

Fig. 3. The schematic of passage technique

The time-of-flight-diffraction (TOFD) ultrasonic detection method has been widely used in defect detection and sizing performance in engineering structures [10], [11]. The TOFD technique is based on diffraction of ultrasonic energy from tips of discontinuities, instead of geometrical reflection on the interface of the discontinuities. The diffracted component can therefore be received by suitably positioned ultrasonic transducers. A buried crack in a specimen is located between a transmitter and a receiver [10]. It has higher accuracy for measuring the through-wall size of crack-like defects, and can be obtained in a wide range of material thickness [9]. The method is gaining popularity because of its high probability of detection, low false call rate-and most importantly, its intrinsic accuracy in flaw sizing, especially in depth.

TOFD should be combined with the Pulse Echo technique, to get full coverage. Pulse-echo has high defect detection rates for surface-breaking and near surface defects, but is poor on interior defect detection. These two methods are complementary [9].

\subsection{AIM AND SCOPE}

The paper describes the development of multipoint ultrasonic diagnostics system used for assessment of technical condition of T-shaped bridge beams. The system should be easy to mount on the beam, both in the factory as well as at the construction site and the screen must provide quick information if the beam is damaged or not. The device should be a reliable tool for the beam quality control just after production process, during assembly and even after the assembly into bridge superstructure.

The scope of this work includes the description of device, development of the damage detection algorithms and virtual tests of the algorithms on the numerical data. The tests have been conducted on the several possible damage scenarios selected with use of the advices of the engineers and the experience gained form the in situ tests of T-shaped beam [8]. It is intended that the proposed device can detect presence of cracks and their approximate locations. 
2. Diagnostic DeVice And PROCEDURES FOR MUltipoint DETECTION SYSTEM

\subsection{Device}

The device uses nine transducers located on the beam web sides and beam bottom (Figure 4). The most sensitive place for cracks development in the T-shaped beam is the bottom side of the element due to the possible inaccuracies during prestressing process and concrete curing. In addition the bottom part of the beam is subjected to tension forces during the transportation and assembly. The piezoelectric transducers are mounted to the concrete surface by coupling agents and if necessary they are pressed to the beam by additional external frame. The coupling between transducers and the beam is a very important issue but is not within the scope of this paper. Each sensor is wired and connected to the data acquisition hardware. The measuring signal are conditioned, digitalized and recorded on a portable computer unit. The damage detection algorithm is applied and the information on the element condition is issued on the screen. The details on transducers location are shown in Figure 5.

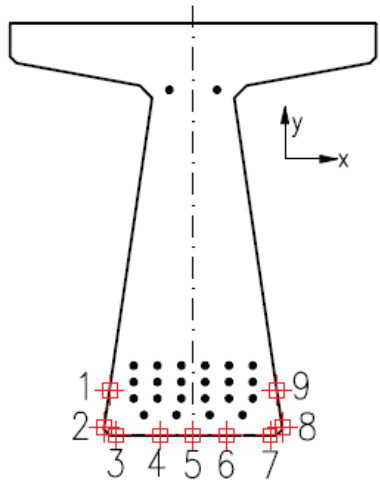

Fig. 4. Proposed location of the transducers

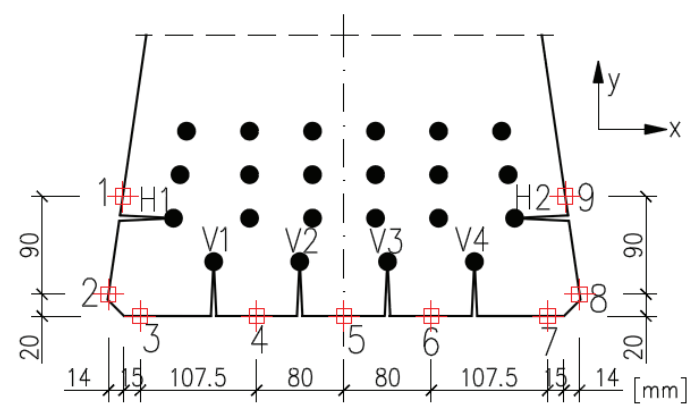

Fig. 5. The details on the transducers location and the assumed location of the cracks 
The location of all cracks taken into account is shown in Figure 5. According to the gained experience the cracks can developed in the vicinity of two bottom rows of the prestressing cables. Therefore, it is assumed that in the worst case 2 horizontal and 4 vertical cracks can develop.

\subsection{THE ALGORITHM OF THE METHOD}

For the selected configuration of the multipoint diagnostic system a damage detection algorithm has been developed. The device generates the wave packet by the first transducer producing the wave travelling through the element. The wave is recorded by all nine transducers. Then, the second transducer generates the wave packet and again all nine transducers record the signals. The wave excitation is conducted for all nine transducers. The measurements are completed when all 162 ( 9 excitations in 9 transducers in 2 directions) signals are recorded.

Figure 6 shows the block diagram of the proposed algorithm. The decision if the beam is damaged or not is drawn with use of indices $p_{i}$ computed form the collected data. The algorithm uses 6 indices derived to detect the crack and its location.

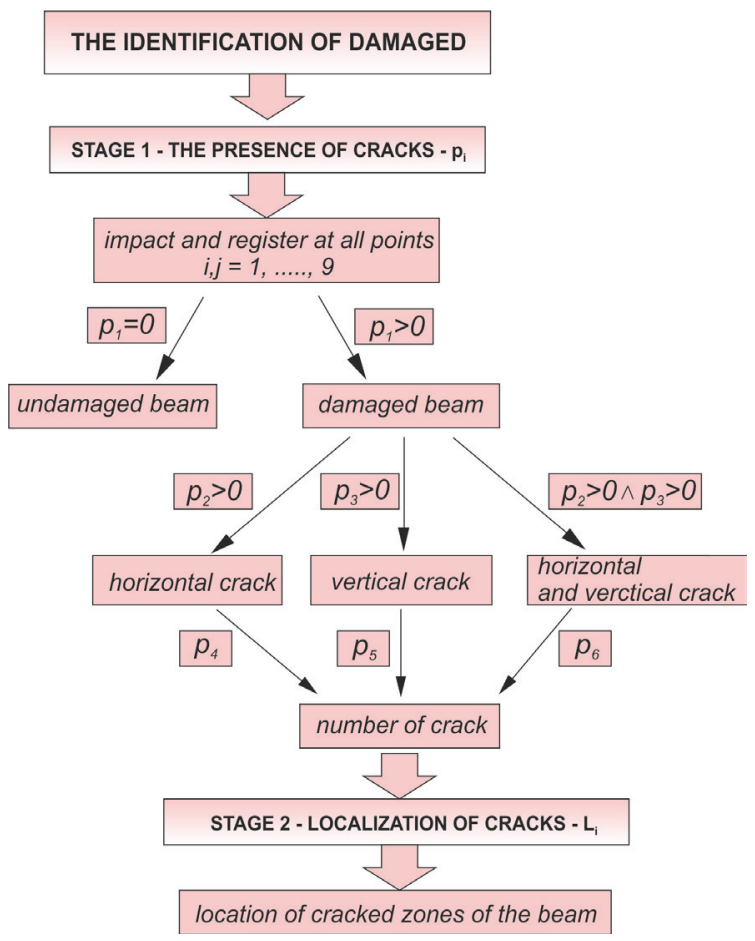

Fig. 6. Block diagram of the damage detection algorithm 
First it is necessary to check a global index $p_{l}(2.1)$, which indicates whether the beam is damaged or not. If $p_{1}$ parameter equals zero the beam is undamaged, if $p_{1}>0$ further analysis must be conducted. The search for the horizontal and vertical cracks is done with use of indices $p_{2}$ and $p_{3}$. These parameters are calculated from the formulas (2.2) and (2.3) stated below:

$$
\begin{gathered}
p_{1}=\sum_{i, j=1}^{9} S_{i j}=\sum_{i=1}^{9}\left(\sum_{j=1}^{9} S^{x}+\sum_{j=1}^{9} S^{y}\right) \\
p_{2}=\sum_{i=1}^{2}\left(\sum_{j=1}^{2} S^{x}+\sum_{j=1}^{2} S^{y}\right)+\sum_{i=8}^{9}\left(\sum_{j=8}^{9} S^{x}{ }_{i j}+\sum_{j=8}^{9} S^{y}\right) \\
p_{3}=\sum_{i=2}^{2}\left(\sum_{j=8}^{8} S^{x}{ }_{i j}+\sum_{j=8}^{8} S^{y}{ }_{i j}\right)+\sum_{i=8}^{8}\left(\sum_{j=2}^{2} S^{x}{ }_{i j}+\sum_{j=2}^{2} S^{y}\right)
\end{gathered}
$$

where $i$ stands for number of the point where wave has been generated and $j$ is a number of the point where the wave has been recorded (Figure 5). The algorithm of the method is presented in Figure 6.

The parameter $S_{i j}$ is defined based on the knowledge of the time of flight for damaged and undamaged beam. The factor $S_{i j}$ indicates if there is damage on the wave path from point $i$ to point $j$. The superscripts $x$ and $y$, in $S_{i j}^{x}$ and $S_{i j}^{y}$, denote the acceleration direction $x$ and $y$, respectively. The parameters $S_{i j}$ can take value 0 which indicates undamaged case and value 1 that shows presence of damage.

The time of flight ratio, i.e., time of flight for damaged beam, $t_{h i j}^{d}$, over the time of flight for undamaged beam, $t_{h i j}^{u d}$, is defined as follows:

$$
T_{i j}=\frac{t_{h i j}^{d}}{t_{h i j}^{u d}}
$$

The time of flight ratio (2.4) is used to check whether the time of flight of a tested beam is different form the time of flight of the undamaged beam. If the parameter $T_{i j}$ is larger than $1+\varepsilon$ the value of $S_{i j}$ is set to 1 and if $T_{i j}<(1+\varepsilon) S_{i j}$ is equal to 0 . The permissible error is denoted by $\varepsilon$ and it is selected individually for the specific concrete element and used hardware.

The number of cracks is determined by dividing the global index $p_{l}$ by the reference value determined for the specific type of damage. The number of cracks for horizontal, vertical as well as horizontal and vertical cracks is calculate based on the appropriate indices $p_{4}, p_{5}, p_{6}$ according to the following formulas: 


$$
p_{4}=\frac{p_{1}}{\sum_{i, j=1}^{g} S_{i j}^{H 1}}
$$

$$
p_{5}=\frac{p_{1}}{\sum_{i, j=1}^{g} S_{i j}^{V 1}}
$$

$$
p_{6}=\frac{p_{1}}{\frac{1}{2} * \sum_{i, j=1}^{9} S_{i j}^{H 1}-V 1}
$$

where $S^{H 1}{ }_{i j}$ denotes parameter $S_{i j}$ for the case of horizontal crack (H1), $S^{V 1}{ }_{i j}$ denotes parameter for the case of vertical crack (V1) and $S^{H I_{-}{ }^{V I}}{ }_{i j}$ is computed for the horizontal and vertical cracks $(\mathrm{H} 1, \mathrm{~V} 1)$. The superscripts with letter $\mathrm{H}$ or $\mathrm{V}$ denote the corresponding crack pattern.

\section{Simulations of wave propagation in a t-Shaped BeAm}

Verification of the damage detection algorithm was performed on numerical data. The simulations have been carried out in ABAQUS/Explicit. The geometry of the prestressed T-beam is shown in Fig. 1. The beam is made of concrete with Young's modulus $\mathrm{E}=37.5 \mathrm{GPa}$, Poisson's ratio $\mathrm{v}=0.2$, density $\rho=2500 \mathrm{~kg} / \mathrm{m}^{3}$. The prestressed steel reinforcement has the following properties: $\mathrm{E}=180 \mathrm{GPa}, \mathrm{v}=0.3, \rho=7500 \mathrm{~kg} / \mathrm{m}^{3}$. It is assumed that there is no damping.

To numerically describe the wave propagation phenomena CPE3 finite element was applied, where the letter "C" indicates continuum element, "PE" - a plane strain element, and " 3 " denotes a 3-node element with full integration. CPE3 element is characterized by linear shape functions. The mesh of the T-beam is shown in Figure 7. The numerical simulations of wave propagation require a special attention to the problem of a sufficiently refined mesh to ensure the correctness of the calculations. The mesh size depends on the wave length and due to application of ultrasonic waves of short lengths, the use of very fine mesh is necessary. In the performed calculations the size of applied element was $1,5 \mathrm{~mm}[8]$.

In order to obtain data for several damage scenarios for validation of damage algorithm several FEM models have been developed: model of the undamaged beam, models for the beam with all possible combinations of horizontal cracks (H1, H2), models for the beam with all possible combinations of and vertical cracks (V1, V2, V3, V4) as well as models for all possible combinations of horizontal and vertical cracks. In all case the length of the crack is $40 \mathrm{~mm}$. 


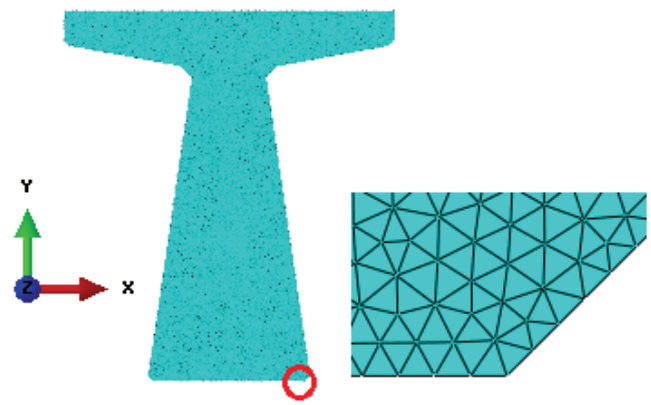

Fig. 7. Mesh of the T-beam model

The numerical simulations were performed for the ultrasonic waves generated by wave packets constructed form sine signal modulated by Hanning window of duration $T_{w}=10^{-5} \mathrm{~s}$ with the central frequency of $f=200 \mathrm{kHz}$ (Figure 8). The time step for integration was $d_{t}=10^{-7} \mathrm{~s}$ and time of integration was $t_{w}=10^{-3} \mathrm{~s}$. The sinusoidal load was generated according to the equation (3.1) and (3.2). The beam was subjected at to loadings at points 1, 2, 8,9 in the $x$ direction and at points 3-7 in the $y$ direction. During excitation at specific point, signals were registered at all nine transducers. For this type of beam frequency $200 \mathrm{kHz}$ can get an exact measurement.

$$
\begin{aligned}
& p(t)=\left\{\begin{array}{ll}
p_{0} \sin \left(2 \pi^{*} f^{*} t\right) * w(t) & t \in\left[0, T_{w}\right] \\
0 & t>T_{w}
\end{array}\right\} \\
& w(t)=0.5\left(1-\cos \left(\frac{2 \pi^{*} f^{*} t}{n_{w}}\right)\right), t \in\left[0, T_{w}\right]
\end{aligned}
$$

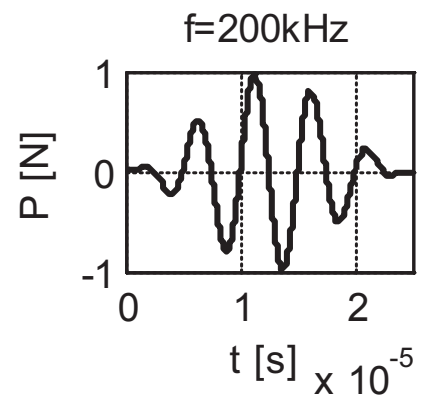

Fig. 8. Wave packet versus time 


\section{TESTS OF THE ALGORIthM}

\subsection{ONE HORIZONTAL CRACK}

The damage detection procedure is based on acceleration signals recorded in each of nine measurement points. Figure 9 shows the case where the beam has only one horizontal crack (H1). For this case all 162 signals are recorded. The examples of the acceleration signals for the undamaged beam (UD) and damaged beam (H1) are limited to data recorded for waves excited at points 1,2 and 3 that are shown in Fig. 10, 11 and 12 , respectively. These figures show the whole computed time signals together with zooms of the selected parts of the time signals from which the time of flights data have been computed.

The values of the wave arrival times at the transducers are also shown in these figures. The wave front is defined by the maximum acceleration of the wave first incoming peak, $a_{h}$, and it is used to determine the values of time of flight. It was assumed that reference acceleration must be larger than the selected threshold set individually for the tested beam and used hardware. In this case the threshold was set to $0.05 \mathrm{~m} / \mathrm{s}^{2}$, and thus, $\left|a_{h}\right| \geq 0,05 \mathrm{~m} / \mathrm{s}^{2}$. All peaks in the signal that are below the threshold value considered as noise.

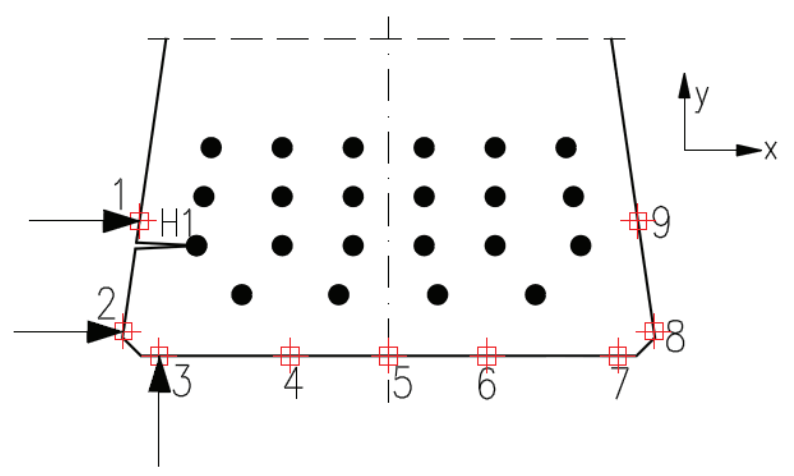

Fig. 9. Example load in points 1, 2, 3 for crack H1

The complete results for the damage case $\mathrm{H} 1$ together with undamaged data (UD) are given in Table 1 . The columns summarizes all the values of $a_{h}$ and $t_{h}$ for loading at the point $i \in(1,9)$ and recording points $j \in(1,9)$, respectively, in the $x$ direction as well as in the $y$ direction. The column denoted by $T_{i j}$ gives the values of the time ratios. The permissible error $\varepsilon$ is set to 0.10 . The last column provides information on the parameters $S_{i j}$.

The indices $\mathrm{p}_{\mathrm{i}}$, for the case of crack $\mathrm{H} 1$, achieve the following values: $p_{1}=14, p_{2}=4$, $p_{3}=0$, and according to the proposed algorithm the diagnostic system shows that there is one horizontal crack since $p_{4}=1$. 
The location of crack can be determined from the time ratio $T_{i j}$ where the subscripts $i$ and $j$ define region were the crack exists. In this case the largest value of the time ratio is $\mathrm{T}_{21}=2.65$ ( $y$ direction) and it corresponds to the location between points 2 and 1 (Figure 9) for $y$ acceleration direction.
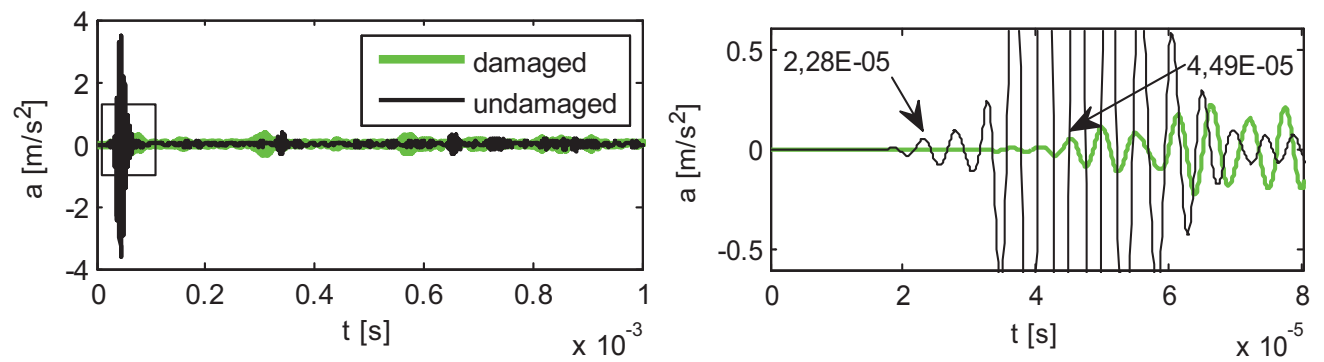

Fig. 10. Acceleration signals for undamaged beam and for beam with $\mathrm{H} 1 \mathrm{crack}$ (loading at point 1 , response at point $2, x$ direction)
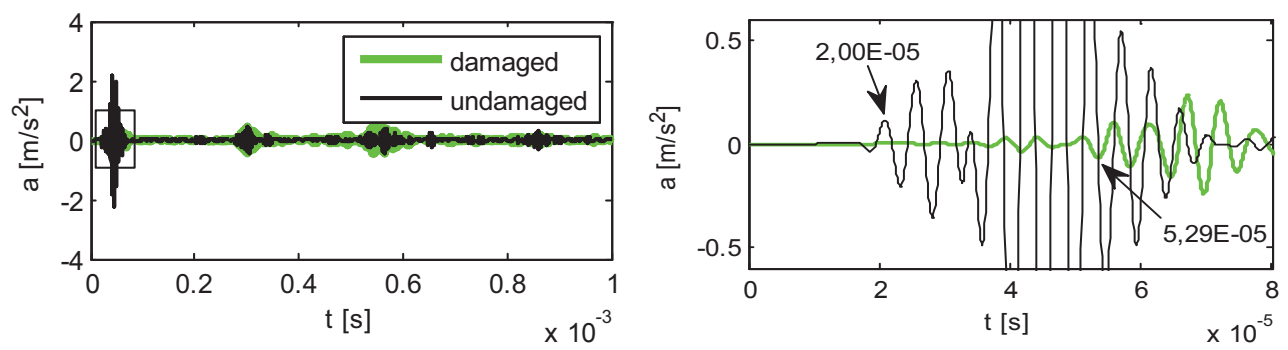

Fig. 11. Acceleration signals for undamaged beam and for beam with $\mathrm{H} 1$ crack (loading at point 2, response at point $1, y$ direction)
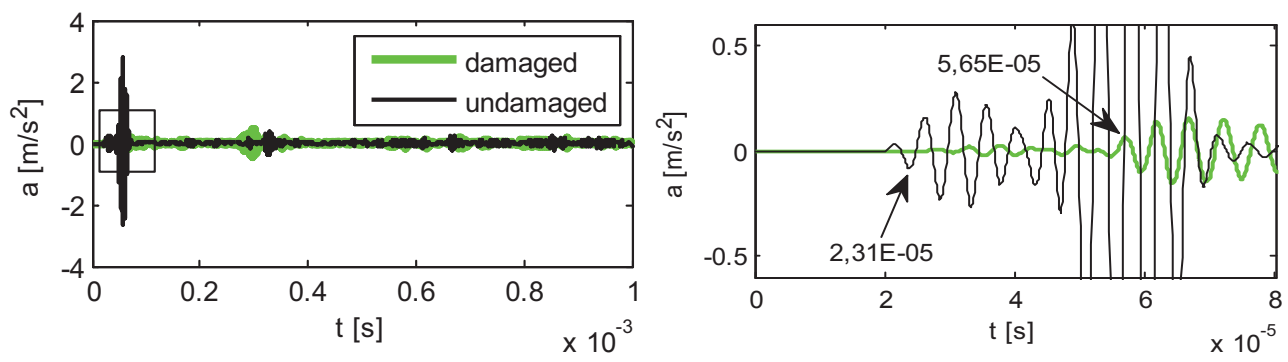

Fig. 12. Acceleration signals for undamaged beam and for beam with $\mathrm{H} 1$ crack (loading at point 3 , response at point $1, x$ direction) 
Table 1

Time of flight for UD and H1 crack

\begin{tabular}{|c|c|c|c|c|c|c|c|}
\hline \multirow{2}{*}{ 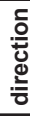 } & \multirow{2}{*}{$\begin{array}{c}\text { register at } \\
\text { point } j:\end{array}$} & \multicolumn{2}{|c|}{ undamaged beam UD } & \multicolumn{2}{|c|}{ damaged beam $\mathrm{H} 1$} & \multirow{2}{*}{$T_{i j}$} & \multirow{2}{*}{$S_{i j}$} \\
\hline & & $a_{h}$ & $t_{h}$ & $a_{h}$ & $t_{h}$ & & \\
\hline \multicolumn{8}{|c|}{ loading at point: $i=1$} \\
\hline \multirow{9}{*}{$\mathbf{x}$} & 1 & $6.87 \mathrm{E}-02$ & $3.00 \mathrm{E}-07$ & $6.86 \mathrm{E}-02$ & $3.00 \mathrm{E}-07$ & 1.00 & 0 \\
\hline & 2 & $5.21 \mathrm{E}-02$ & $2.28 \mathrm{E}-05$ & $5.30 \mathrm{E}-02$ & $4.49 \mathrm{E}-05$ & 1.97 & 1 \\
\hline & 3 & $5.39 \mathrm{E}-02$ & $2.77 \mathrm{E}-05$ & $5.10 \mathrm{E}-02$ & $4.50 \mathrm{E}-05$ & 1.62 & 1 \\
\hline & 4 & $6.09 \mathrm{E}-02$ & $3.22 \mathrm{E}-05$ & $-5.45 \mathrm{E}-02$ & $3.60 \mathrm{E}-05$ & 1.12 & 1 \\
\hline & 5 & $5.02 \mathrm{E}-02$ & $4.34 \mathrm{E}-05$ & $5.16 \mathrm{E}-02$ & $4.43 \mathrm{E}-05$ & 1.02 & 0 \\
\hline & 6 & $5.19 \mathrm{E}-02$ & $5.60 \mathrm{E}-05$ & $5.08 \mathrm{E}-02$ & $5.66 \mathrm{E}-05$ & 1.02 & 0 \\
\hline & 7 & $5.32 \mathrm{E}-02$ & $7.37 \mathrm{E}-05$ & $-5.61 \mathrm{E}-02$ & $7.57 \mathrm{E}-05$ & 1.03 & 0 \\
\hline & 8 & $5.00 \mathrm{E}-02$ & $7.73 \mathrm{E}-05$ & $5.10 \mathrm{E}-02$ & $7.77 \mathrm{E}-05$ & 1.01 & 0 \\
\hline & 9 & $5.14 \mathrm{E}-02$ & $7.34 \mathrm{E}-05$ & $5.28 \mathrm{E}-02$ & $7.34 \mathrm{E}-05$ & 1.00 & 0 \\
\hline \multirow{9}{*}{ y } & 1 & $5.11 \mathrm{E}-02$ & $6.40 \mathrm{E}-06$ & $5.02 \mathrm{E}-02$ & $6.50 \mathrm{E}-06$ & 1.02 & 0 \\
\hline & 2 & $5.39 \mathrm{E}-02$ & $2.26 \mathrm{E}-05$ & $-5.20 \mathrm{E}-02$ & $5.21 \mathrm{E}-05$ & 2.31 & 1 \\
\hline & 3 & $-5.08 \mathrm{E}-02$ & $2.31 \mathrm{E}-05$ & $5.16 \mathrm{E}-02$ & $5.65 \mathrm{E}-05$ & 2.45 & 1 \\
\hline & 4 & $-5.76 \mathrm{E}-02$ & $3.22 \mathrm{E}-05$ & $5.09 \mathrm{E}-02$ & $3.58 \mathrm{E}-05$ & 1.11 & 1 \\
\hline & 5 & $-5.54 \mathrm{E}-02$ & 4.37E-05 & $5.50 \mathrm{E}-02$ & $4.63 \mathrm{E}-05$ & 1.06 & 0 \\
\hline & 6 & $-5.01 \mathrm{E}-02$ & $5.66 \mathrm{E}-05$ & $5.40 \mathrm{E}-02$ & $5.87 \mathrm{E}-05$ & 1.04 & 0 \\
\hline & 7 & $5.23 \mathrm{E}-02$ & $7.59 \mathrm{E}-05$ & $-5.27 \mathrm{E}-02$ & $7.82 \mathrm{E}-05$ & 1.03 & 0 \\
\hline & 8 & $5.04 \mathrm{E}-02$ & $8.02 \mathrm{E}-05$ & $-5.33 \mathrm{E}-02$ & $8.25 \mathrm{E}-05$ & 1.03 & 0 \\
\hline & 9 & $-5.21 \mathrm{E}-02$ & $1.09 \mathrm{E}-04$ & $5.45 \mathrm{E}-02$ & $1.15 \mathrm{E}-04$ & 1.06 & 0 \\
\hline & & & & & & $\sum S_{1 j}=$ & 6 \\
\hline \multicolumn{8}{|c|}{ loading at point: $i=2$} \\
\hline$x$ & 1 & $5.21 \mathrm{E}-02$ & $2.28 \mathrm{E}-05$ & $5.30 \mathrm{E}-02$ & $4.49 \mathrm{E}-05$ & 1.97 & 1 \\
\hline$y$ & 1 & $5.13 \mathrm{E}-02$ & $2.00 \mathrm{E}-05$ & $-5.30 \mathrm{E}-02$ & $5.29 \mathrm{E}-05$ & 2.65 & 1 \\
\hline & & & & & & $\sum S_{2 j}=$ & 2 \\
\hline \multicolumn{8}{|c|}{ loading at point: $i=3$} \\
\hline $\mathbf{x}$ & 1 & $-5.08 \mathrm{E}-02$ & $2.31 \mathrm{E}-05$ & $5.16 \mathrm{E}-02$ & $5.65 \mathrm{E}-05$ & 2.45 & 1 \\
\hline$y$ & 1 & $-5.58 \mathrm{E}-02$ & $2.11 \mathrm{E}-05$ & $5.03 \mathrm{E}-02$ & $3.96 \mathrm{E}-05$ & 1.88 & 1 \\
\hline & & & & & & $\sum S_{3 j}=$ & 2 \\
\hline \multicolumn{8}{|c|}{ loading at point: $i=4$} \\
\hline $\mathbf{x}$ & 1 & $-5.76 \mathrm{E}-02$ & $3.22 \mathrm{E}-05$ & $5.09 \mathrm{E}-02$ & $3.58 \mathrm{E}-05$ & 1.11 & 1 \\
\hline$y$ & 1 & $5.38 \mathrm{E}-02$ & $3.22 \mathrm{E}-05$ & $-5.21 \mathrm{E}-02$ & $4.04 \mathrm{E}-05$ & 1.25 & 1 \\
\hline & & & & & & $\sum S_{4 j}=$ & 2 \\
\hline \multicolumn{8}{|c|}{ loading at point: $i=5$} \\
\hline $\mathbf{x}$ & 1 & $-5.35 \mathrm{E}-02$ & $4.59 \mathrm{E}-05$ & $5.24 \mathrm{E}-02$ & $5.31 \mathrm{E}-05$ & 1.16 & 1 \\
\hline \multirow{2}{*}{\multicolumn{8}{|c|}{ loading at point: $i=6$}} \\
\hline & & & & & & & \\
\hline$y$ & 1 & $5.06 \mathrm{E}-02$ & $6.10 \mathrm{E}-05$ & $-5.08 \mathrm{E}-02$ & $6.80 \mathrm{E}-05$ & 1.11 & 1 \\
\hline & & & & & & $\sum S_{6 j}=$ & 1 \\
\hline \multicolumn{8}{|c|}{ loading at point: $i=7$} \\
\hline & & & & & & $\sum S_{7 j}=$ & 0 \\
\hline \multicolumn{8}{|c|}{ loading at point: $i=8$} \\
\hline & & & & & & $\sum S_{8 j}=$ & 0 \\
\hline \multicolumn{8}{|c|}{ loading at point: $i=9$} \\
\hline & & & & & & $\sum S_{9 j}=$ & 0 \\
\hline & & & & & & & $s_{i j}=$ \\
\hline
\end{tabular}




\subsection{ONE HORIZONATAL AND TWO VERTICAL CRACKS}

The same procedures, as described in the previous section, were conducted for the damage scenario with one horizontal crack (H1) and two vertical cracks (V1 and V2) showed in Figure 13. This crack pattern is denoted by the symbol H1_V1_V2.

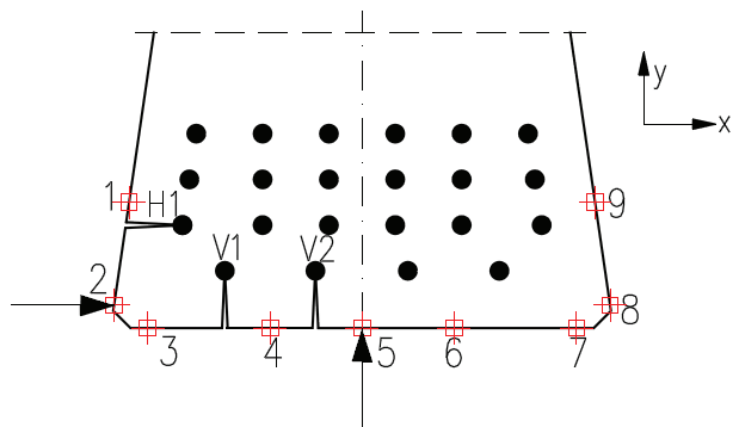

Fig. 13. Location of loading points for the crack pattern H1_V1_V2
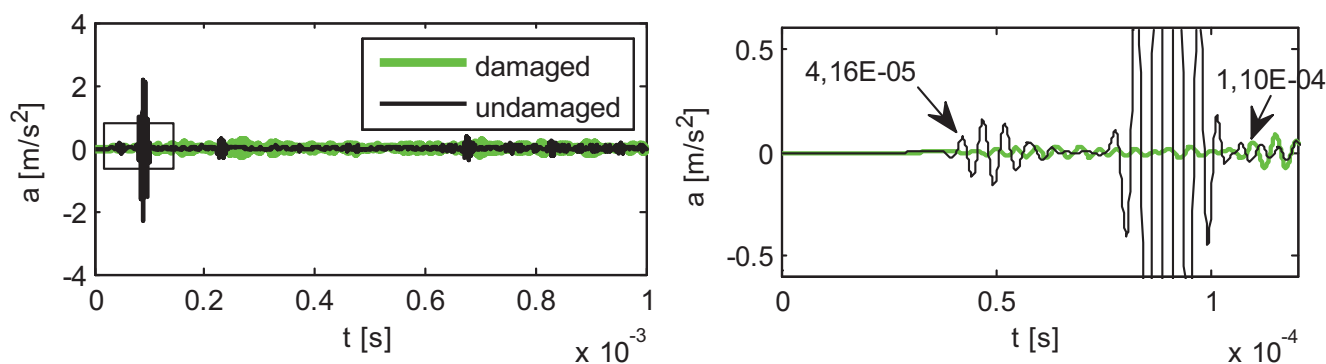

Fig. 14 Acceleration signals for undamaged beam and for beam with H1_V1_V2 crack pattern (loading at point 2 , response at point $5, x$ direction)
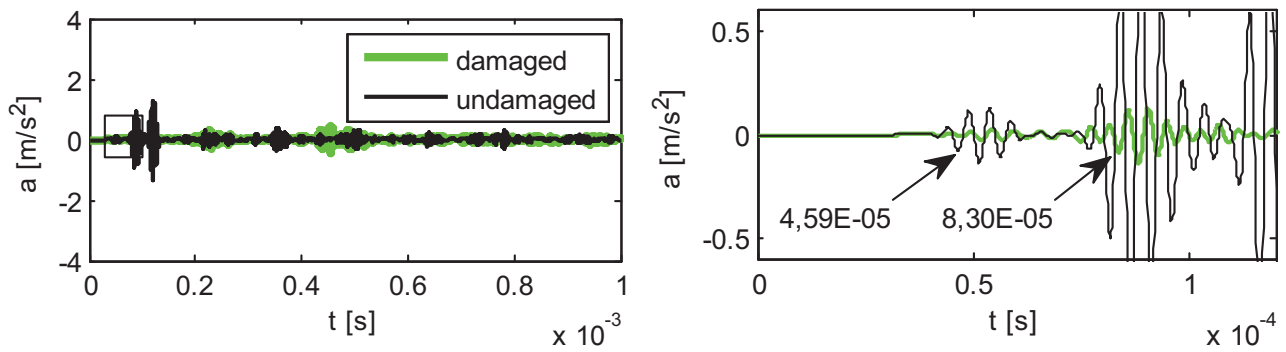

Fig. 15 Acceleration signals for undamaged beam and for beam with H1_V1_V2 crack pattern (loading at point 5 , response at point $1, y$ direction) 
The example of the $x$ direction acceleration signals of the damaged and undamaged beam for the wave generated at point 2 and recorded at point 5 are shown in Figure 14. The $y$ direction acceleration signals for the wave generated at point 5 and recorded at point 1 are shown in Figure 15. In this case the complicated reflection and refraction phenomena have more influence on the acceleration signals than in case of the simple crack pattern with only one horizontal crack. Nevertheless, the time of flight for each signal can be determined and corresponding time of flight ratios can be calculated. The largest values of the time of flight ratio are: $T_{21}=2.66$ ( $y$ direction), $T_{25}=2.64$ ( $x$ direction), $T_{35}=2.12$ ( $x$ direction). They correctly indicate that the damage region is located between points 1 and 2 as well as 2 and 5 (Figure 13). The selected data of peak accelerations of the wave front, time of flights, time ratios and parameters $S_{i j}$ are given in Table 2.

\subsection{Summary FOR ALl CONSIDERED DAMAGE SCENARIOS}

The tests of all considered damage scenarios have been conducted. Some of the results are summarized in Table 3. Three cases of the crack patterns are shown, i.e., one horizontal crack, two cases of vertical cracks and three crack patters for combination of horizontal and vertical cracks. The table shows the sums $\sum S_{i j}$, parameter $p_{1}$ and number of cracks indicators $p_{4}, p_{5}$ and $p_{6}$. In the simplest cases, when there is only one crack, the number of cracks indicators $p_{4}, p_{5}$ and $p_{6}$ have values equal to 1 . However, in case of two or more cracks values of $p_{4}, p_{5}$ and $p_{6}$ can be expressed by a rational number. Since the number of cracks must be expressed by a natural number the indicators $p_{4}, p_{5}$ and $p_{6}$ are calculated by rounding them up to the nearest natural number. The rational values of $p_{4}, p_{5}$ and $p_{6}$ as well the final values showing number of cracks are given in the last column of Table 3. Note that the verifications of the proposed damage algorithms showed that the system correctly detects the number of the cracks for each considered damage scenarios.

To improve the automation of the search for the location of the crack a parameter $L_{i}$ has been introduced. It is calculated as an average value of two neighboring expressions $\sum S_{i j}$. The term "neighboring" means that subscripts $i$, in both neighboring expressions, have a difference equal to 1 . The largest values of $L_{i}$ are colored in grey and they indicate the possible location of the damage. 
Table 2

Time of flight for UD and H1_V1_V2 crack

\begin{tabular}{|c|c|c|c|c|c|c|c|c|c|c|c|c|c|c|c|}
\hline \multirow{2}{*}{ 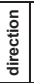 } & \multirow{2}{*}{$\begin{array}{c}\text { register } \\
\text { at point } \\
j:\end{array}$} & \multicolumn{2}{|c|}{ undamaged beam UD } & \multicolumn{2}{|c|}{ damaged beam H1_V1_V2 } & \multirow{2}{*}{$T_{i j}$} & \multirow{2}{*}{$\mathrm{S}_{\mathrm{ij}}$} & \multirow{2}{*}{ 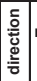 } & \multirow{2}{*}{$\begin{array}{c}\text { register at } \\
\text { point } j:\end{array}$} & \multicolumn{2}{|c|}{ undamaged beam UD } & \multicolumn{2}{|c|}{ damaged beam H1_V1_V2 } & \multirow{2}{*}{$\mathbf{T}_{\mathrm{ij}}$} & \multirow{2}{*}{$\mathbf{s}_{\mathrm{ij}}$} \\
\hline & & $a_{h}$ & $t_{h}$ & $a_{h}$ & $t_{h}$ & & & & & $a_{h}$ & $t_{h}$ & $a_{h}$ & $t_{h}$ & & \\
\hline \multicolumn{8}{|c|}{ loading at point: $i=1$} & \multicolumn{8}{|c|}{ loading at point: $i=4$} \\
\hline \multirow{4}{*}{$x$} & 2 & $5.21 \mathrm{E}-02$ & $2.28 \mathrm{E}-05$ & $5.02 \mathrm{E}-02$ & $4.48 \mathrm{E}-05$ & 1.96 & 1 & \multirow{7}{*}{ y } & 1 & $5.38 \mathrm{E}-02$ & $3.22 \mathrm{E}-05$ & $5.08 \mathrm{E}-02$ & 4.27E-05 & 1.33 & 1 \\
\hline & 3 & $5.39 \mathrm{E}-02$ & $2.77 \mathrm{E}-05$ & $5.28 \mathrm{E}-02$ & 4.52E-05 & 1.63 & 1 & & 2 & $-5.02 \mathrm{E}-02$ & 3.83E-05 & $5.12 \mathrm{E}-02$ & 4.61E-05 & 1.20 & 1 \\
\hline & 4 & $6.09 \mathrm{E}-02$ & $3.22 \mathrm{E}-05$ & $5.17 \mathrm{E}-02$ & $3.82 \mathrm{E}-05$ & 1.19 & 1 & & 3 & $5.30 \mathrm{E}-02$ & $2.56 \mathrm{E}-05$ & $5.41 \mathrm{E}-02$ & 4.09E-05 & 1.60 & 1 \\
\hline & 5 & $5.02 \mathrm{E}-02$ & 4.34E-05 & $5.02 \mathrm{E}-02$ & 4.96E-05 & 1.14 & 1 & & 5 & $5.41 \mathrm{E}-02$ & $2.06 \mathrm{E}-05$ & $-5.23 \mathrm{E}-02$ & $3.53 \mathrm{E}-05$ & 1.71 & 1 \\
\hline \multirow{4}{*}{$y$} & 2 & $5.39 \mathrm{E}-02$ & $2.26 \mathrm{E}-05$ & $-5.14 \mathrm{E}-02$ & 5.21E-05 & 2.31 & 1 & & 6 & $5.05 \mathrm{E}-02$ & $3.97 \mathrm{E}-05$ & $5.12 \mathrm{E}-02$ & $6.15 \mathrm{E}-05$ & 1.55 & 1 \\
\hline & 3 & $-5.08 \mathrm{E}-02$ & $2.31 \mathrm{E}-05$ & $-5.02 \mathrm{E}-05$ & $5.41 \mathrm{E}-05$ & 2.34 & 1 & & 7 & $5.37 \mathrm{E}-02$ & $9.22 \mathrm{E}-05$ & $-5.13 \mathrm{E}-02$ & 1.15E-04 & 1.24 & 1 \\
\hline & 4 & $-5.76 \mathrm{E}-02$ & 3.22E-05 & $5.14 \mathrm{E}-02$ & $3.60 \mathrm{E}-05$ & 1.12 & 1 & & 9 & $5.09 \mathrm{E}-02$ & $6.10 \mathrm{E}-05$ & $-5.19 \mathrm{E}-02$ & $9.84 \mathrm{E}-05$ & 1.61 & 1 \\
\hline & 5 & $-5.54 \mathrm{E}-02$ & 4.37E-05 & $-5.05 \mathrm{E}-02$ & 4.96E-05 & 1.14 & 1 & & & & & & & $\sum \mathrm{S}_{4 \mathrm{j}}=$ & 15 \\
\hline & & & & & & $\sum S_{1 j}=$ & 8 & \multicolumn{8}{|c|}{ loading at point: $i=5$} \\
\hline \multicolumn{8}{|c|}{ loading at point: $i=2$} & & 1 & $-5.54 \mathrm{E}-02$ & 4.37E-05 & $-5.05 \mathrm{E}-02$ & 4.96E-05 & 1.14 & 1 \\
\hline & 1 & $5.21 \mathrm{E}-02$ & $2.28 \mathrm{E}-05$ & $5.02 \mathrm{E}-02$ & 4.48E-05 & 1.96 & 1 & & 2 & $5.18 \mathrm{E}-02$ & 4.41E-05 & $-5.26 \mathrm{E}-02$ & $6.98 \mathrm{E}-05$ & 1.58 & 1 \\
\hline & 4 & $-5.03 \mathrm{E}-02$ & $2.61 \mathrm{E}-05$ & $-5.03 E-02$ & $3.86 \mathrm{E}-05$ & 1.48 & 1 & $x^{x}$ & 3 & $5.18 \mathrm{E}-02$ & $3.95 \mathrm{E}-05$ & $-5.08 \mathrm{E}-02$ & 7.15E-05 & 1.81 & 1 \\
\hline$x$ & 5 & $5.49 \mathrm{E}-02$ & 4.16E-05 & $5.03 \mathrm{E}-02$ & $1.10 \mathrm{E}-04$ & 2.64 & 1 & & 4 & $-5.78 \mathrm{E}-02$ & 1.83E-05 & $-5.06 \mathrm{E}-02$ & 4.06E-05 & 2.22 & 1 \\
\hline & 6 & $-5.32 \mathrm{E}-02$ & $5.76 \mathrm{E}-05$ & $5.02 \mathrm{E}-02$ & 8.16E-05 & 1.42 & 1 & & 1 & $-5.35 \mathrm{E}-02$ & $4.59 \mathrm{E}-05$ & $-5.68 \mathrm{E}-02$ & 8.30E-05 & 1.81 & 1 \\
\hline & 7 & $5.04 \mathrm{E}-02$ & 7.85E-05 & $5.02 \mathrm{E}-02$ & 1.16E-04 & 1.47 & 1 & $y$ & 3 & $5.55 \mathrm{E}-02$ & $6.49 \mathrm{E}-05$ & $-5.01 \mathrm{E}-02$ & $7.31 \mathrm{E}-05$ & 1.13 & 1 \\
\hline & 8 & $-5.01 \mathrm{E}-02$ & 8.05E-05 & $5.00 \mathrm{E}-02$ & 1.15E-04 & 1.42 & 1 & & 4 & $5.41 \mathrm{E}-02$ & 2.06E-05 & $-5.23 \mathrm{E}-02$ & $3.53 \mathrm{E}-05$ & 1.71 & 1 \\
\hline & 1 & $5.13 E-02$ & $2.00 \mathrm{E}-05$ & $-5.06 \mathrm{E}-02$ & 5.32E-05 & 2.66 & 1 & & & & & & & $\sum S_{5 j}=$ & 7 \\
\hline & 4 & $-5.37 \mathrm{E}-02$ & $2.80 \mathrm{E}-05$ & $-5.01 \mathrm{E}-02$ & $4.21 \mathrm{E}-05$ & 1.50 & 1 & & & & loadir & ig at point: $i=$ & & & \\
\hline $\mathbf{y}$ & 5 & $5.18 \mathrm{E}-02$ & $4.41 \mathrm{E}-05$ & $-5.26 \mathrm{E}-02$ & $6.98 \mathrm{E}-05$ & 1.58 & 1 & & 2 & $5.53 \mathrm{E}-02$ & $1.04 \mathrm{E}-04$ & $5.07 \mathrm{E}-02$ & 1.18E-04 & 1.14 & 1 \\
\hline & 6 & $5.53 \mathrm{E}-02$ & 1.04E-04 & $5.07 \mathrm{E}-02$ & 1.18E-04 & 1.14 & 1 & $x$ & 3 & $5.14 \mathrm{E}-02$ & $5.84 \mathrm{E}-05$ & $5.20 \mathrm{E}-02$ & 9.20E-05 & 1.58 & 1 \\
\hline & 9 & $-5.03 \mathrm{E}-02$ & 8.47E-05 & $5.19 \mathrm{E}-02$ & 1.45E-04 & 1.71 & 1 & & 4 & $5.50 \mathrm{E}-02$ & 3.47E-05 & $5.00 \mathrm{E}-02$ & $6.14 \mathrm{E}-05$ & 1.77 & 1 \\
\hline & & & & & & $\sum S_{2 j}=$ & 11 & & 1 & $5.06 \mathrm{E}-02$ & $6.10 \mathrm{E}-05$ & $5.03 \mathrm{E}-02$ & 1.02E-04 & 1.67 & 1 \\
\hline & & & loadi & g at point: $i=$ & & & & 15 & 4 & 5.05E-02 & $3.97 \mathrm{E}-05$ & $5.12 \mathrm{E}-02$ & $6.15 \mathrm{E}-05$ & 1.55 & 1 \\
\hline & 1 & $-5.08 \mathrm{E}-02$ & $2.31 \mathrm{E}-05$ & $-5.02 \mathrm{E}-02$ & $5.41 \mathrm{E}-05$ & 2.34 & 1 & & & & & & & $\sum \mathrm{S}_{6 \mathrm{j}}=$ & 5 \\
\hline$x$ & 4 & $5.17 \mathrm{E}-02$ & $2.31 \mathrm{E}-05$ & $-5.09 \mathrm{E}-02$ & $4.01 \mathrm{E}-05$ & 1.74 & 1 & & & & loadir & gat point: $i=$ & & & \\
\hline$x$ & 5 & $-5.18 \mathrm{E}-02$ & 3.95E-05 & $-5.12 \mathrm{E}-02$ & 8.39E-05 & 2.12 & 1 & $\mathbf{x}$ & 4 & $-5.60 \mathrm{E}-02$ & $9.30 \mathrm{E}-05$ & $-5.42 \mathrm{E}-02$ & 1.17E-04 & 1.26 & 1 \\
\hline & 9 & $-5.18 \mathrm{E}-02$ & $7.59 \mathrm{E}-05$ & $-5.13 \mathrm{E}-02$ & $8.75 \mathrm{E}-05$ & 1.15 & 1 & $\mathrm{y}$ & 4 & $5.37 \mathrm{E}-02$ & $9.22 \mathrm{E}-05$ & $-5.13 \mathrm{E}-02$ & $1.15 \mathrm{E}-04$ & 1.24 & 1 \\
\hline & 1 & $-5.58 \mathrm{E}-02$ & $2.11 \mathrm{E}-05$ & $5.12 \mathrm{E}-02$ & 3.96E-05 & 1.88 & 1 & & & & & & & $\sum S_{7 j}=$ & 2 \\
\hline y & 4 & $5.30 \mathrm{E}-02$ & $2.56 \mathrm{E}-05$ & $5.41 \mathrm{E}-02$ & 4.09E-05 & 1.60 & 1 & & & & loadir & g at point: $i=$ & & & \\
\hline & 5 & $5.55 \mathrm{E}-02$ & $6.49 \mathrm{E}-05$ & $-5.01 \mathrm{E}-02$ & 7.31E-05 & 1.13 & 1 & & 2 & $5.01 \mathrm{E}-02$ & $8.05 \mathrm{E}-05$ & $-5.00 \mathrm{E}-02$ & 1.15E-04 & 1.42 & 1 \\
\hline & & & & & & $\sum S_{3 j}=$ & 7 & $x$ & 3 & $-5.04 \mathrm{E}-02$ & $7.85 \mathrm{E}-05$ & $-5.92 \mathrm{E}-02$ & $1.11 \mathrm{E}-04$ & 1.42 & 1 \\
\hline & & & loadi & g at point: $i=$ & & & & & 4 & $5.36 \mathrm{E}-02$ & $5.76 \mathrm{E}-05$ & $-5.57 \mathrm{E}-02$ & $1.29 \mathrm{E}-04$ & 2.24 & 1 \\
\hline & 1 & $-5.76 \mathrm{E}-02$ & $3.22 \mathrm{E}-05$ & $5.14 \mathrm{E}-02$ & $3.60 \mathrm{E}-05$ & 1.12 & 1 & $\mathrm{y}$ & 4 & $5.39 \mathrm{E}-02$ & $1.04 \mathrm{E}-04$ & $-5.19 \mathrm{E}-02$ & $1.21 \mathrm{E}-04$ & 1.16 & 1 \\
\hline & 2 & $-5.37 \mathrm{E}-02$ & $2.80 \mathrm{E}-05$ & $-5.01 \mathrm{E}-02$ & $4.21 \mathrm{E}-05$ & 1.50 & 1 & & & & & & & $\sum S_{8 \mathrm{j}}=$ & 4 \\
\hline & 3 & $-5.13 \mathrm{E}-02$ & $2.31 \mathrm{E}-05$ & $-5.33 \mathrm{E}-02$ & $4.80 \mathrm{E}-05$ & 2.08 & 1 & & & & loadir & g at point: $i=$ & & & \\
\hline$x$ & 5 & $5.75 \mathrm{E}-02$ & $1.83 \mathrm{E}-05$ & $5.00 \mathrm{E}-02$ & $4.41 \mathrm{E}-05$ & 2.41 & 1 & $\mathbf{x}$ & 4 & $-5.19 \mathrm{E}-02$ & $5.60 \mathrm{E}-05$ & $-5.11 \mathrm{E}-02$ & $6.28 \mathrm{E}-05$ & 1.12 & 1 \\
\hline $\mathbf{x}$ & 6 & $-5.47 \mathrm{E}-02$ & 3.47E-05 & $5.24 \mathrm{E}-02$ & 7.55E-05 & 2.18 & 1 & & 2 & $5.01 \mathrm{E}-02$ & $8.02 \mathrm{E}-05$ & $5.02 \mathrm{E}-02$ & $9.75 \mathrm{E}-05$ & 1.22 & 1 \\
\hline & 7 & $-5.17 \mathrm{E}-02$ & 5.84E-05 & $-5.45 \mathrm{E}-02$ & 1.15E-04 & 1.98 & 1 & $y$ & 3 & $5.18 \mathrm{E}-02$ & $7.59 \mathrm{E}-05$ & $5.13 \mathrm{E}-02$ & $8.75 \mathrm{E}-05$ & 1.15 & 1 \\
\hline & 8 & $-5.39 \mathrm{E}-02$ & $1.04 \mathrm{E}-04$ & $5.19 \mathrm{E}-02$ & $1.21 \mathrm{E}-04$ & 1.16 & 1 & & 4 & $-5.00 \mathrm{E}-02$ & $5.66 \mathrm{E}-05$ & $-5.15 \mathrm{E}-02$ & $6.27 \mathrm{E}-05$ & 1.11 & 1 \\
\hline & 9 & $5.00 \mathrm{E}-02$ & $5.66 \mathrm{E}-05$ & $5.15 \mathrm{E}-02$ & $6.27 \mathrm{E}-05$ & 1.11 & 1 & & & & & & & $\sum S_{9 j}=$ & 4 \\
\hline & & & & & & & & & & & & & & & $\sum S_{i j}=63$ \\
\hline
\end{tabular}


Table 3

Indices and parameters of damage detection algorithms for selected damage patterns

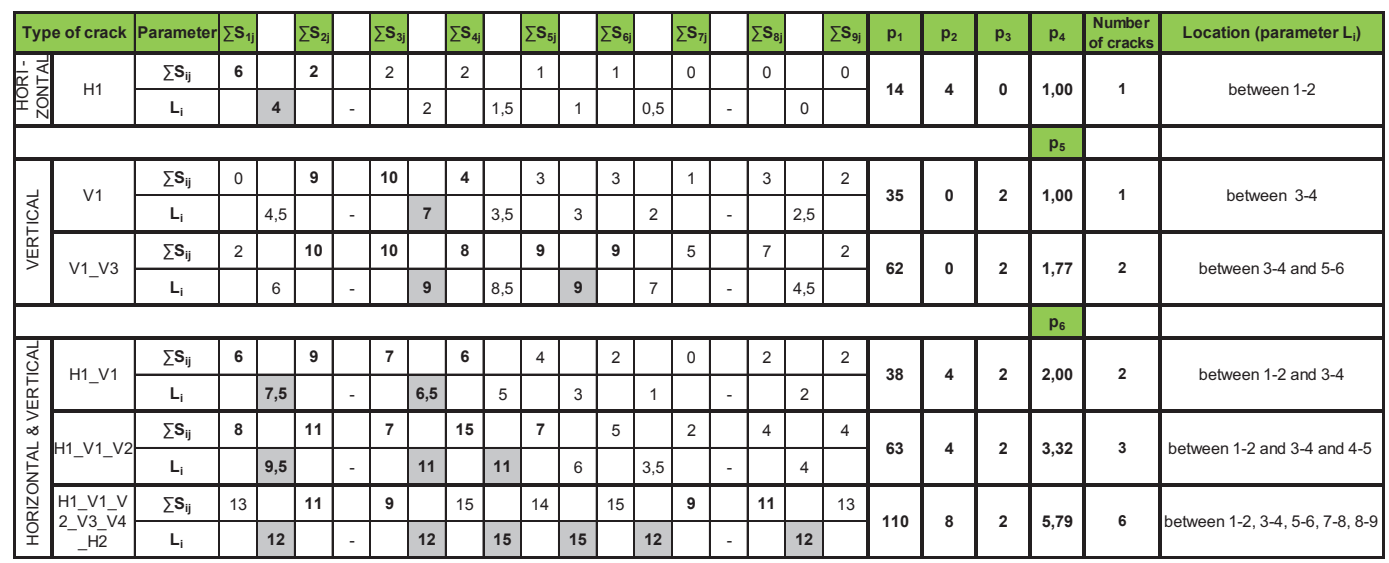

\section{Conclusions}

This paper discuses a development of a device for damage detection of the prefabricated concrete T-beam used in bridge structures. The aim of the study is to develop simple to install and reliable device for a beam quality control on each stage of the element live cycle.

The multipoint ultrasonic diagnostic system consists of nine transducers located on the beam's web sides and bottom. The system automatically recognizes whether the beam is damaged and where the cracks are located. The damage detection algorithm is based on ratios between the time of flight in damaged and undamaged beam and set of proposed indices and parameters that lead to computation of number of cracks and their location.

Verification of damage detection algorithm has been performed for different crack patterns consisting of all possible combination of two horizontal and four vertical cracks located in the bottom part of the beam. The parametric numerical simulations with the use of a wave packets excitation proved that the acceleration signals are expedient and delivers necessary information to determine the presence of damage. The final results proved that proposed diagnostic method can be successfully applied for assessment the technical condition of the prefabricated T-beams.

The presented study is a first stage of development of ultrasonic device dedicated to prefabricated, prestressed concrete T-beams. The numerical "experiments" showed that the device is capable of correct detection of number of crack and can indicate crack's location. However, the study on the numerically obtained signals cannot imitate all complex details of ultrasonic waves propagation in concrete elements. The next stage 
i.e., the experimental tests on a real concrete element, will provide the most valuable knowledge on applicability and accuracy of the proposed device.

\section{ACKNOWLEDGMENTS}

The work reported in this paper has been supported by the project POIG 01.01.02-10106/09 "Innovative means and effective methods to improve the safety and durability of building structures and transportation infrastructures in the strategy of sustainable development" within the Operational Programme Innovative Economy 2007-2013 co-financed from EU resources.

\section{REFERENCES}

1. Adamczewski G., Nicał A., Large-dimension prefabricated concrete elements (in Polish), Inżynier budownictwa, 3, 46-53, 2012

2. Cieśla J., Biskup M., Gałat A., Skawiński M., Precast concrete bridge beams compressed In Poland - history - state of the art, Przegląd budowlany, 4, 19-23, 2013

3. Rucka M., Wilde K.: Non-destructive diagnostics of concrete cantilever beam and slab by impact echo method. Diagnostyka, 3, 63-68, 2010

4. J. Hoła, K. Schabowicz, State-of-the-art non-destructive methods for diagnostic testing of building structures - anticipated development trends, Archives of Civil and Mechanical Engineering, X (3) (2010) 5-18

5. A. Garbacz, Non-destructive assessment of repair efficiency with impact-echo and ultrasonic methods - an overview, International Conference on Concrete Repair, Rehabilitation and Retrofitting (ICCRRR) Cape Town, South Africa, 2005.

6. Sansalone M.J., Street W.B. Impact Echo. Nondestructive Evaluation of Concrete and Masory. Bullbrier Press, Ithaca, N.Y., 1997

7. Drobiec Ł., Jasiński R., Piekarczyk A.: Defect localization methods of concreto structures - the ultrasonic method (in Polish), Przegląd Budowlany, 9, 29-36, 2007

8. Mariak A., Rucka M., Wilde K.: Ultrasonic diagnostics of concrete T-beams used in bridge structures. Proceedings of the $4^{\text {th }}$ German-Polish PhD Symposium: Current Scientific Challenges in Concrete and Steel Structures, Material Technology and Structural Fire Protection

9. Michael Moles, Luke Robertson, Tony Sinclair, Developments in Time-Of-Flight Diffraction (TOFD), 18th World Conference on Nondestructive Testing, 16-20 April 2012, Durban, South Africa

10. Yonghong Zhang, Yu Wang, Ming J. Zuo, Xiaodong Wang, Ultrasonic Time -of- Flight diffraction crack size identification based on cross-correlation, Department of Mechanical Engineering, University of Alberta, Edmonton, Canada T6G 2G8

11. J. P. Charlesworth, J. A. G. Temple. Engineering application of ultrasonic time-of-flight-diffraction, Second edition, London: Research Studies Press Ltd, 2001 
